\title{
LETTERS
}

\section{Early referral for hoarseness}

It is with great interest that I read the article by Morgan and Rigby regarding hoarseness of unclear origin in adults. ${ }^{1}$ The article summarizes five key messages for primary care providers for the diagnosis and management of hoarseness.

The recent updated clinical practice guideline on hoarseness (dysphonia) from the American Academy of Otolaryngology-Head and Neck Surgery Foundation reinforces some of the same points. ${ }^{2}$ It recommended against treatment of hoarseness with antireflux medications, corticosteroids and antimicrobials without visualization of the larynx.

One of the important changes in the updated guideline is a recommendation for an earlier referral. Specifically, the guideline recommended either to perform laryngoscopy or to refer the patient for laryngoscopy when dysphonia fails to resolve or improve within four weeks, or when a serious underlying cause is suspected irrespective of the duration of dysphonia. This recommendation suggests much earlier referral than the previously suggested time frame of three months and is of importance for primary care providers.

\section{Courtney Artur Gevorgyan MD}

Otolaryngologist, and head and neck surgeon, Lakeridge Health Oshawa, Oshawa, Ont.

Cite as: CMAJ 2018 September 10; 190:E1087. doi: 10.1503/cmaj.69758

\section{References}

1. Morgan AP, Rigby MH. Hoarseness of unclear origin in adults. CMAJ 2018;190:E80.

2. Stachler RJ, Francis DO, Schwartz SR, et al. Clinical practice guideline: hoarseness (dysphonia) (update). Otolaryngol Head Neck Surg 2018;158(Suppl 1): S1-S42.

Competing interests: None declared. 